\title{
Postoperative epidural analgesia in thoracic surgery: continuous administration by electric push-syringe diffusion versus elastomeric diffuser
}

Rachid Cherkab', Mohamed Lazraq ${ }^{1 *}$, Zakaria Elhafid', Wafaa Haddad', Chafik Elkettani', Lahoucine Barrou', Souheil Boubia² and Mohamed Ridai

*Correspondence: mohamed_lz@hotmail.com

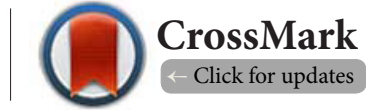

${ }^{1}$ Anesthesia And Intensive Care, Central Reanimation, Ibn Rochd Universitary Hospital, Casablanca, Morocco.

${ }^{2}$ Department Of Thoracic Surgery, Ibn Rochd Universitary Hospital, Casablanca, Morocco.

\begin{abstract}
Objectives: Thoracotomy is the cause of severe postoperative pain and prolonged (3-5 days) purveyors of multiple complications mainly respiratory ones. The thoracic epidural analgesia (TEA) is currently considered as the "gold standard" analgesic. This technique requires prolonged hospitalization in intensive care unit (ICU) to administer continuous mixing (local anesthetic+opioid) using an electric syringe pump (ESP).

Purpose: If elastomeric pumps (EP) have already demonstrated their effectiveness in orthopedics and visceral surgery, their place in TEA remains unclear. We report our experience with their use for the maintenance of TEA in thoracic surgery.

Materials and methods: All consecutive patients operated January to June 2012 for lung surgery (lobectomy, pneumonectomy or atypical resection) by thoracotomy were studied prospectively in the early postoperative period (first 5 days) in ICU.The patients were operated under general anesthesia (GA) and TEA is systematically proposed, the epidural catheter is in place at T4-T5 before induction of GA. Postoperatively, patients were randomized into 2 groups: group A received a mixture containing a local anesthetic (LA), in this case $0.125 \%$ bupivacaine and morphine (fentanyl: $1 \mathrm{mg} / \mathrm{ml}$ of AL). This mixture was continuously administered to the patient using an ESP while Group B received the same mixture from an EP. Several parameters were analyzed during the 96 hours post-operative sensory level, Bromage score, complications, analgesic consumption, visual analogue scale (VAS) at rest, cough and mobilization as well as overall patient satisfaction.
\end{abstract}

Results: After thoracotomy, continuous administration of a mixture containing $0.125 \%$ bupivacaine associated to fentanyl through an epidural catheter with a PE provides effective postoperative analgesia with few side effects.

Conclusion: To reduce the cost of hospitalization in the ICU and reduce consumption of analgesics after surgery, the PE could be used in surgical services subject to rigorous monitoring, and continues with a highly trained nursing staff.

Keywords: Thoracic-surgery, epidural-analgesia, elastomeric-diffuser, electric-pump

\section{Introduction}

Thoracotomy causes severe postoperative and prolonged pains (3-5 days), providing multiple complications mainly respiratory but also hemodynamic neuroendocrine changes, with hypercatabolism particularly deleterious in patients with comorbidities. It also represents an obstacle to respiratory physiotherapy and postoperative care [1].

The thoracic epidural is currently considered as the "gold 
standard" analgesic. This technique requires prolonged hospitalization in intensive care unit (ICU) in order to administer continuous mixing (local+opioid anesthetics) using electric push syringe (EPS) $[\mathbf{6}, 7]$.

If the elastomeric diffusors (ED) have already proved their efficiency in the fields of orthopedics [2], and visceral surgery $[3,18]$, their place in the thoracic epidural remains unclear.

We report our experience about their use for the maintenance of postoperative thoracic epidural by elastomeric diffusers.

\section{Materials and methods}

From January to June 2012, all the consecutive patients who have undergone a lung resection surgery (lobectomy, pneumonectomy, or atypical resection) based on a thoracotomy, were studied prospectively in precocious postoperative period (the 5 first days) in the ICU.

After the approval by the local ethical committee, seventy ASA I and II patients were included in our study after obtaining their written informed consent.

The exclusion criteria consisted in: patients ASA III and IV, refusal or contraindication of thoracic epidural catheter, sepsis, association of another surgical approach such as a laparotomy or a sternotomy, previous reaction to local anesthetics or opioids, chronic renal failure, technical failure by displacement or malposition of the catheter, hemodynamic instability and the need for prolonged ventilatory support in the postoperative period.

The various stages of the surgical procedure are explained to the patients during preanesthetic consultation and preanesthetic visit the day before surgery in collaboration with thoracic surgeons. Also, all patients were premedicated by using hydroxysine.

Once in the operating room and after the implementation of a standard monitoring, all the patients benefitted systematically from an epidural catheter, realized by an anaesthesiologist in the T4-T5 space.

After the induction of the anesthesia, the intubation is realized by a double-lumen tube (ROBERTSHAW).

In the postoperative period, the patients were randomized into 2 groups: group A receiving a mixture including a local anesthetics (LA), in this case bupivacaine $0.125 \%$, and an opioid (fentanyl $1 \mathrm{mg} / \mathrm{ml}$ of LA). This mixture was continuously administered to the patient using a PSE, while group B received the same mixture from ED.

The used elastomeric diffuser is type Accufuser CTx ${ }^{\circledR}$ (550 $\mathrm{ml}$ volume) with a flow rate about 5 or $8 \mathrm{ml} / \mathrm{h}$.

After the operation, all the patients have been hospitalized in the intensive care unit, with supervision; by continuous monitoring during the 96 hours after the operation; of the rhythm rate (scope), the cardiac rate, the non invasive blood pressure, the respiratory rate, the saturation oxygen $(\mathrm{SpO} 2)$ as well as the neurological status.

The various parameters that have been collected are: the extent of the motor block (Bromage score : Table 1) and sensory level, the quality of analgesia assessed by the VAS (visual analogue scale) at rest, the effort and the cough, the use of local anesthetics,
Table 1. Modified bromage score (epidural motor block).

1: Complete motor block
2: Almost complete motor block (move your feet)
3: Partial block (move feet and knees)
4: Weakness discoverable by the hip flexion
5: No weakness of the hip in the supine position
6: Knee flexion standing with support
7: Knee flexion standing without support

opioids and other analgesics, complications, mobilization and the overall patient fulfillment.

The desaturation was defined by a $\mathrm{SpO} 2<90 \%$, the respiratory depression with a respiratory rate less than $10 \mathrm{cycles} / \mathrm{min}$, the sedation by Ramsay score $\geq 3$, the hypotension with a SBP $<90$ $\mathrm{mm} \mathrm{Hg}$ or a decrease of more than $30 \%$ relative to basic values, and the bradycardia by HR $50 \mathrm{bpm}$ and the tachycardia by a $\mathrm{HR} \geq 100$.

The clinical supervision has also looked for complications such as signs of respiratory distress (sweating, circulation, activation of the accessory respiratory muscles), neurological distress (drowsiness, nervousness, feeling of metallic savor in the mouth, lip paresthesia, restlessness, yawn , tremor, nystagmus, logorrhea, headache, nausea, tinnitus, convulsions, depression of the central nervous system deficit signs paresis/paresthesia of the upper/lowerlimbs) secondary to epidural hematoma or in connection with LA toxicities, side effects attribuable to morphine (pruritus, nausea, urinary retention), local state of the dressings as well as the drains.

The supervision concerned also the system of administration of the analgesic mixture with search for stopping of the administration after a kinking of the catheter or with antiparticle filter, a failure of the self-syringe pusher or DE and a leakage of analgesic mixture.

The statistical study made use of software Epi-Info version 5 . The importance of the tests has been retained for $\mathrm{P}<0.05$.

\section{Results}

Both groups of patients had similar features and there was no significant difference regarding the age, the sex, and the ASA class. The average age was $57 \pm 8$ years for group A versus $63 \pm 10$ years for group $B(p=0.83)$. In both groups, there was a male predominance with a sex ratio of $29 / 6$ in group $A$ and $27 / 8$ in group $B(p=0.52)$. In group $A, 74.2 \%$ of the patients were classified as ASA I and $25.8 \%$ ASAII, while in group B, $68.5 \%$ of the patients were classified as ASA I $(\mathrm{p}=0.75)$ and $31.5 \%$ were classified as ASA II ( $\mathrm{p}=0.59)$ (Table 2).

The indication for the surgery was dominated by the neoplastic disease. The lobectomy represented the most frequently practiced operation without significant difference between the two groups ( $82.9 \%$ vs $77.1 \%$ respectively). The pneumonectomy was achieved in $11.4 \%$ of the patients in group A versus $14.3 \%$ in group B 
$(\mathrm{p}=0.67)$, while the atypical resection was realized in $5.7 \%$ of the patients in group A against $8.6 \%$ in group B $(\mathrm{p}=0.57)$ (Table 2).

The duration of surgery was similar in both groups (145 min+/60 in group A and 152+/-65 in group B, $\mathrm{p}=0.76$ ).

The valuation of the analgesia by VAS score showed no significant difference between the two groups during the 96 hours after the surgery whatever it was; at rest or during the cough (and/or mobilization). Thus, at the moment of the cough, 65.7\% of the patients in group $\mathrm{A}$ had a score of $0 \mathrm{~mm}$ against $57.1 \%$ of the patients in group B, and $23 \%$ reported a score between 1 and 3 in group A against $28.6 \%$ of the cases in group $B(p=0.61$ and 0.53 respectively). Also, $11.3 \%$ had a score greater than 3 $\mathrm{mm}$ in the first group versus $14.3 \%$ in the second group (0.64). Moreover, all the patients in the 2 groups had a VAS score of less than $3 \mathrm{~mm}$ at rest (Table $\mathbf{3}$ ).

Regarding the complications, no patient in both groups presented signs of respiratory or neurological distress related to epidural catheter placement or the AL toxicity. One patient in each group presented a pneumopathy. On the contrary, 2 patients in group A presented a postoperative rhythm disorders but without hemodynamic repercussions.

The patients' satisfaction was better in group B without significant difference: $88.4 \%$ in group A against $94.3 \%$ in group

Table 2. Characteristics of the patients and surgery.

\begin{tabular}{llll}
\hline Parameters & $\begin{array}{l}\text { Group A } \\
\text { N=35 }\end{array}$ & $\begin{array}{l}\text { Group B } \\
\mathbf{N = 3 5}\end{array}$ & P \\
\hline Age (years) & $57 \pm 8$ & $63 \pm 10$ & 0.83 \\
Sex (M/F) & $29 / 6$ & $27 / 8$ & 0.52 \\
ASA score & & & \\
1 & $74.2 \%$ & $68.5 \%$ & 0.75 \\
2 & $25.8 \%$ & $31.5 \%$ & 0.59 \\
Indication for surgery & & & \\
Lung cancer & $65.7 \%$ & $71.4 \%$ & 0.75 \\
Hydatid cyst & $20 \%$ & $14.3 \%$ & 0.41 \\
Bronchectasia & $8.6 \%$ & $5.7 \%$ & 0.50 \\
$\begin{array}{l}\text { Other } \\
\text { Surgical procedure }\end{array}$ & $5.7 \%$ & $8.6 \%$ & 0.57 \\
$\begin{array}{l}\text { Lobectomy } \\
\text { Pneumectomy }\end{array}$ & $82.9 \%$ & $77.1 \%$ & 0.77 \\
$\begin{array}{l}\text { Atypical resection } \\
\text { Duration of the }\end{array}$ & $11.4 \%$ & $14.3 \%$ & 0.67 \\
operation & $5.7 \%$ & $8.6 \%$ & 0.57 \\
\hline
\end{tabular}

Table 3. Valuation of the EVA and patients satisfaction.

\begin{tabular}{llll}
\hline Parameters & Group A & Group B & P \\
\hline EVA at rest & & & \\
$0 \mathrm{~mm}$ & $74 \%$ & $80 \%$ & 0.77 \\
$1-3 \mathrm{~mm}$ & $26 \%$ & $20 \%$ & 0.50 \\
$>3 \mathrm{~mm}$ & $0 \%$ & $0 \%$ & 0.0 \\
EVA when coughing/ & & & \\
mobilization & & & \\
$0 \mathrm{~mm}$ & $65.7 \%$ & $57.1 \%$ & 0.61 \\
$1-3 \mathrm{~mm}$ & $23 \%$ & $28.6 \%$ & 0.53 \\
$>3 \mathrm{~mm}$ & $11.3 \%$ & $14.3 \%$ & 0.64 \\
Patient satisfaction & $88.5 \%$ & $94.3 \%$ & 0.8 \\
\hline
\end{tabular}

\section{B $(\mathrm{p}=0.8)$ (Table 3).}

Moreover, $11.5 \%$ of the patients of group A patients experienced at least one episode of hypotension against $8.5 \%$ in group $B(p=0.63)$. The motor block has been noticed in $3 \%$ of the cases in Group A against 5.7\% of cases in group B but the difference is not significant ( $\mathrm{p}=0.48)$, and the urinary retention was noted only in 2 patients in group A (Table 4). No deaths are noticed in both group of study during the study period.

Table 4. Complications.

\begin{tabular}{llll}
\hline Parameters & Group A & Group B & P \\
\hline Respiratory complications: & & & \\
Desaturation & 0 & 0 & -- \\
Atelectasis & 0 & $3 \%(\mathrm{n}=1)$ & 0.31 \\
Pneumopathy & $3 \%(\mathrm{n}=1)$ & $3 \%(\mathrm{n}=1)$ & 1 \\
Rhythm disorder & $5.7 \%(\mathrm{n}=2)$ & 0 & 0.15 \\
General complications: & & & \\
Hypotension & $11.5 \%(\mathrm{n}=4)$ & $8.5 \%(\mathrm{n}=3)$ & 0.63 \\
Motor block & $3 \%(\mathrm{n}=1)$ & $5.7 \%(\mathrm{n}=2)$ & 0.48 \\
Urinary retention & $5.7 \%(\mathrm{n}=2)$ & $0 \%(\mathrm{n}=0)$ & 0.15 \\
\hline
\end{tabular}

\section{Discussion}

The postoperative pain after thoracotomy is particularly intense and prolonged. Moreover, this type of surgery often leads to chronic pains that may continue for months or years [5].

It has been emphasized that the effecting of a strategy for perioperative analgesia "incisive" has a positive impact on the postoperative complications as well as on the incidence of chronic pain. In this context, the locoregional analgesia techniques have a prominent place: obtaining an analgesia effort that permits an effective rehabilitation and a precocious mobilization.

Given the intensity of the postoperative pain, the locoregional techniques are the only ones that achieve effective effort analgesia. Classically, the epidural analgesia is the "gold standard" for certain authors, all the patients who must undergo a thoracotomy should benefit from peridural analgesia $[6,7,10-14]$.

Several publications showed the important role of the DE, in the management of postoperative pain after orthopedic [2], visceral [3-20], or gyneco-obstetrical [23] surgery, as well as the ambulatory management of the pain in cancerous patients [22].

The elastomeric diffuser is a sterile disposable medical device, operating through a reservoir bag elastomer requiring neither electrical power source nor the effect of the gravity. The mobile $\mathrm{DE}$ consists of an elastomer reservoir and a flow regulator that allow diffusion of the solution at a rate fixed by the Poiseuille law. The flow rate depends on several factors such as the internal diameter of the flow regulator, its length, the pressure difference at both ends of the flow regulator, the viscosity and the density of the solution [21].

These devices are widely used for peri-neural continuous postoperative administration of local anesthetics with reduction of the consumption of various oral or parenteral analgesics which facilitate the precocious postoperative rehabilitation $[\mathbf{2 , 4 , 1 5 , 1 6}$. The benefits of the elastomeric pumps are multiple compared 
to electronic pumps: the portability, the ease of use, with less technical problems such as false alarms even its absence may mask abnormal administration of medicines [2].

Dadure et al., [8] reported, in the course of a clinical series, about elastomeric devices ( 2 to $9 \mathrm{ml} / \mathrm{h}$ ), weighed at the beginning and the end of the infusion, that the rate flow of ED remains between their rates determined by the manufacturers $\pm 10 \%$.

The main drawback according to the authors is the inability to change the flow of administration [17].

In our study, the quality of the analgesia was comparable in both groups, and we didn't notice significant increase in analgesic requirements even if the flow of these elastomers diffusers was determined.

Also, the patients' satisfaction was better in the group B but the difference isn't significant, given all the advantages of the $\mathrm{DE}$ are: liberty of movement (reduction of the thromboembolic risk), low weight, and no alarms. Thus, the use of these devices appeared safe without complications compared to the control group. In our study, no technical problems occurred with the DE that we used.

Up to now, no study has evaluated the DE in postoperative epidural analgesia in thoracic surgery compared to the syringe pump.

In the thoracic surgery, Tsujiguchi et al., [19] evaluated the accuracy of the elastomeric diffuser (Coopdech Syrinjector ${ }^{\circledR}$ ), in continuous epidural infusion. A continuous epidural infusion of the bupivacaine $(0.25 \%)$ was introduced in the immediate postoperative period with a flow rate of 2 or $3 \mathrm{ml} / \mathrm{h}$. The results were satisfactory for clinical use of continuous epidural infusion of the bupivacaine. However, when the pump is reused or the volume of local anesthetic residual is less than $10 \mathrm{ml}$, the accuracy of perfusion would potentially be inaccurate.

Grayson H. et al., [9] evaluated these devices using a catheter along the thoracotomy incision and showed satisfactory results. In our context, the use of elastomeric diffusers has reduced the length of hospitalization in the units of intensive care in half. The patients are transferred to the department of thoracic surgery after 2 days. The DE are maintained five days with close supervision provided by qualified staff.

\section{Conclusion}

After thoracotomy, the continuous administration of a mixture comprising the bupivacaine $0.125 \%$ associated with fentanyl via an epidural catheter with a DE provides effective postoperative analgesia with few side effects. To reduce the cost of hospitalization in the units of resuscitation and reduce the postoperative analgesic consumption, the elastomeric diffuser could be used in the surgical departments of rigorous, permanent and highly qualified staff.

\section{Competing interests}

The authors declare that they have no competing interests.

\section{Authors' contributions}

All authors contributed significantly to the execution and interpretation of data. They have participated in revising the manuscript for intellectual content and approved the manuscript to be published.

\section{Publication history}

Editor: Dario Galante, University Hospital “Ospedali Runiti” of Foggia, Italy.

Received: 22 September 2014 Revised: 16 October 2014

Accepted: 22 October 2014 Published: 31 October 2014

\section{References}

1. Hughes R and Gao F. Pain Control For thoracotomy. Contin Educ Anaesth Crit Care Pain. 2005; 5:56-60.

2. Ganapathy S, Amendola A, Lichfield R, Fowler PJ and Ling E. Elastomeric pumps for ambulatory patient controlled regional analgesia. Can J Anaesth. 2000; 47:897-902. | Article | PubMed

3. Ansaloni L, Agnoletti V, Bettini D, Caira A, Calli M, Catena F, Celotti M, De Cataldis A, Gagliardi S, Gasperoni E, Leone A, Melotti RM, Potalivo A, Simoncini G, Taffurelli M and Di Nino G. The analgesic efficacy of ropivacaine continuous wound instillation Elastomeric pump Effective appendectomy. J Clin Anesth. 2007; 19:256-63.

4. Ilfeld BM, Morey TE and Enneking FK. Portable infusion pumps used for continuous regional analgesia: delivery rate accuracy and consistency. Reg Anesth Pain Med. 2003; 28:424-32. I PubMed

5. Ochroch EA, Gottschalk A, Augostides J, Carson KA, Kent L, Malayaman $\mathrm{N}$, Kaiser LR and Aukburg SJ. Long-term pain and activity falling on recovery from major thoracotomy using thoracic epidural analgesia. Anesthesiology. 2002; 97:1234-1244.

6. Soto RG and Fu ES. Acute pain management for patients undergoing thoracotomy. Ann Thorac Surg. 2003; 75:1349-57. | Article | PubMed

7. Ochroch EA and Gottschalk A. Impact of acute pain and its management for thoracic surgical patients. Thorac Surg Clin. 2005; 15:105-21. | Article I PubMed

8. Dadure C, Raux O, Gaudard P, Sagintaah M, Troncin R, Rochette A and Capdevila X. Continuous psoas compartment blocks after major orthopedic surgery in children: a prospective computed tomographic scan and clinical studies. Anesth Analg. 2004; 98:623-8. | Article | PubMed

9. Wheatley GH, 3rd, Rosenbaum DH, Paul MC, Dine AP, Wait MA, Meyer $\mathrm{DM}$, Jessen ME, Ring WS and DiMaio JM. Improved pain management outcomes with continuous infusion of a local anesthetic after thoracotomy. J Thorac Cardiovasc Surg. 2005; 130:464-8. | Article | PubMed

10. Adolphs J, Schmidt DK, Mousa SA, Kamin B, Korsukewitz I, HabazettI $\mathrm{H}$, Schafer $\mathrm{M}$ and Welte $\mathrm{M}$. Thoracic epidural anesthesia attenuates hemorrhage-induced impairment of intestinal perfusion in rats. Anesthesiology. 2003; 99:685-92. | Article | PubMed

11. Kabon B, Fleischmann E, Treschan T, Taguchi A, Kapral S and Kurz A. Thoracic epidural anesthesia tissue oxygenation Increase falling on major abdominal surgery. Anesth Analg. 2003; 97:1812-7.

12. Ballantyne JC, Carr DB, deFerranti S, Suarez T, Lau J, Chalmers TC, Angelillo IF and Mosteller F. The comparative effects of postoperative analgesic therapies on pulmonary outcome: cumulative meta-analyses of randomized, controlled trials. Anesth Analg. 1998; 86:598-612. | Article I PubMed

13. Rigg JR, Jamrozik K, Myles PS, Silbert BS, Peyton PJ, Parsons RW and Collins KS. Epidural anaesthesia and analgesia and outcome of major surgery: a randomised trial. Lancet. 2002; 359:1276-82. | Article | PubMed

14. Chandrashekar MV, Irving M, Wayman J, Raimes SA and Linsley A. Immediate extubation and epidural analgesia allow safe management in a high-dependency unit Effective two internship oesophagectomy. Results of eight years of experience in a Specialized upper gastrointestinal unit in a district general hospital. Br J Anaesth. 2003; 90:474-9.

15. Klein SM, Grant SA, Greengrass RA, Nielsen KC, Speer KP, White W, 
Warner DS and Steele SM. Interscalene brachial plexus block with a continuous catheter insertion system and a disposable infusion pump. Anesth Analg. 2000; 91:1473-8. I Article I PubMed

16. Savoie FH, Field LD, Jenkins RN, Mallon WJ and Phelps RA, 2nd. The pain control infusion pump for postoperative pain control in shoulder surgery. Arthroscopy. 2000; 16:339-42. I Article I PubMed

17. Ilfeld BM, Morey TE and Enneking FK. Portable infusion pumps used for continuous regional analgesia: delivery rate accuracy and consistency. Reg Anesth Pain Med. 2003; 28:424-32. I PubMed

18. Beaussier M, El'Ayoubi H, Schiffer E, Rollin M, Parc Y, Mazoit JX, Azizi L, Gervaz P, Rohr S, Biermann C, Lienhart A and Eledjam JJ. Continuous preperitoneal infusion of ropivacaine provides effective analgesia and accelerates recovery after colorectal surgery: a randomized, doubleblind, placebo-controlled study. Anesthesiology. 2007; 107:461-8. | Article I PubMed

19. Tsujiguchi N, Fujita S, Kawamata T, Omote K, Matsumoto M and Namiki A [Clinical evaluation of accuracy of a new disposable pump (Syrinjector) for continuous epidural infusion]. Masui. 2000; 49:177-80. | PubMed

20. Ansaloni L, Agnoletti V, Bettini D, Caira A, Calli M, Catena F, Celotti M, De Cataldis A, Gagliardi S, Gasperoni E, Leone A, Melotti RM, Potalivo A, Simoncini G, Taffurelli M and Di Nino G. The analgesic efficacy of continuous elastomeric pump ropivacaine wound instillation after appendectomy. J Clin Anesth. 2007; 19:256-63. | Article I PubMed

21. R. Comolet. Experimental fluid mechanics. Volume II Fluid real turbomachines. 33-34.

22. Negro S, Azuara ML, Sanchez Y, Reyes R and Barcia E. Physical compatibility and in vivo evaluation of drug mixtures for subcutaneous infusion to cancer patients in palliative care. Support Care Cancer. 2002; 10:65-70. | PubMed

23. Banks S and Pavy T. A portable, disposable device for patient-controlled epidural analgesia following Caesarean section: evaluation by patients and nurses. Aust N Z J Obstet Gynaecol. 2001; 41:372-5. | Article | PubMed

\section{Citation:}

Cherkab R, Lazraq M, Elhafid Z, Haddad W, Elkettani $\mathrm{C}$ and Barrou L. Postoperative epidural analgesia in thoracic surgery: continuous administration by electric push-syringe diffusion versus elastomeric diffuser. J Anesthesiol Clin Sci. 2014; 3:8. http://dx.doi.org/10.7243/2049-9752-3-8 